\title{
A origem das fundações públicas de direito privado na saúde brasileira
}

The origin of public foundations of private law in brazilian health

\author{
EstéFani SANDMANn SANDMANn DE Deus \\ Universidade Estadual do Rio Grande do Sul \\ TAINARA RODRIGUES KRUSSER \\ Universidade Estadual do Rio Grande do Sul
}

RESUmo Este artigo efetua uma revisão teórica acerca de uma nova forma de prestação de serviços públicos de saúde brasileira: as Fundações Públicas de Direito Privado. Tal trabalho trata de uma pesquisa de abordagem qualitativa, que por meio da pesquisa bibliográfica e documental apresentará as origens desse novo serviço de saúde. Para compreender sua historicidade, também, se efetuou uma revisão das origens do sistema de saúde brasileiro. Dessa forma, pode-se verificar que as origens das fundações correspondem às reformas gerenciais propostas na administração pública brasileira. E ainda que tais reformas distanciam-se da proposta inicial averiguadas nas origens do sistema de saúde brasileiro.

Palavras-chave: Saúde. Sistema Único de Saúde. Fundações Públicas de Direito Privado.

ABSTRaCT This article carries out a theoretical review about a new way of providing public health services in Brazil: The Public Foundations of Private Law. This work deals with a qualitative research, which through bibliographic and documentary research will present the origins of this new health service. To understand its historicity, a review of the origins of the Brazilian health system was also carried out. Thus, it can be seen that the origins of the foundations correspond to the managerial reforms proposed in the Brazilian public administration. And even though such reforms are distant from the initial proposal verified in the origins of the Brazilian health system.

Keywords: Health. Unified Health System. Public Foundations of Private Law. 


\section{INTRODUÇÃO}

Este artigo destina-se a esclarecer as origens de novas formas de administração pública, como as fundações públicas de direito privado, inseridas no Brasil na década de 1990. Far-se-á um recorte teórico a partir do surgimento da Nova Gestão Pública (NGP), inserida no Brasil, por meio do Plano Diretor da Reforma do Aparelho do Estado (Pdrae), iniciado no ano de 1994. Além disso, pretende-se estudar como tais fundações se inseriram em nossa saúde pública e, para tanto, será feita uma leitura acerca do SUS: suas origens e suas alterações em função da NGP.

Em contraponto ao modelo gerencial, será efetuado um breve histórico do SUS brasileiro, desde suas origens, no Movimento Sanitarista, até as novidades implementadas atualmente, como as fundações públicas de direito privado. Tais fatores são importantes para delimitarem os momentos históricos importante na construção desse modelo de saúde. E, além disso, se corresponderam responder à questão principal deste trabalho que trata de verificar quais as origens das fundações públicas de direito privado na saúde brasileira?

Para realização deste trabalho, será utilizado o método qualitativo (FLICK, 2009), que aponta que a pesquisa qualitativa usa o texto como material empírico; além disso, ela parte da noção da construção social das realidades em estudo e se interessa pelas perspectivas dos participantes (FLICK, 2009). Trata-se, portanto, de verificar como ocorreram as mudanças na administração pública brasileira, que introduziram o gerencialismo à esfera pública e modificaram algumas formas de prestação de serviços públicos.

O trabalho será dividido em duas partes: Primeiro, será elucidado o processo que funcionará para originar as novas formas de prestação de serviços públicos: o Gerencialismo. Após, será abordada a linha histórica da saúde brasileira no intuito de responder como esses dois momentos ao convergirem correspondem à criação de um novo modo, em expansão, dos serviços públicos.

\section{O GERENCIALISMO NO BRASIL}

Antes de falar sobre fundações públicas de direito privado, há que se ressaltar que as fundações públicas de direito público começaram a aflorar na Idade Moderna, depois do Renascimento e da Reforma (PAES, 1998).

No Brasil, no século XVIII, a origem de rabisco das fundações pode ser dada a partir da criação da Fundação Romão de Matos Duarte. A fundação que tinha patrimônio próprio funcionava com a Santa Casa do Rio (RAFAEL, 1997).

Legalmente, só se ouviu falar em fundações no início do século XX. Segundo Rafael (1997), foi consolidado fundação como o ordenamento jurídico positivo do instituto fundacional como pessoa jurídica de direito privado, dotada de um patrimônio composto por bens livres destinados a uma finalidade social determinada.

Para compreender as origens das Fundações Públicas de direito privado é importante entender que a administração pública brasileira é composta por dois conjuntos de agentes, órgãos e entidades atuantes para resolução dos serviços públicos, são eles: a administração pública direta e a administração pública indireta. A administração direta integra os órgãos 
conectados ao poder central, em cada esfera de governo, como os ministérios da Saúde, do Trabalho etc. Já a administração indireta é composta por entidades com personalidade jurídica diferenciada, como as fundações e as autarquias, que foram criadas com a intenção de realizar atividades públicas de forma descentralizada, conforme a necessidade da administração pública. Toda essa organização é resultado de um longo processo legislativo, que possui como seu principal marco legal a Constituição Federal de 1988, o decreto Lei $n^{\circ}$. 200, de 1967, e suas respectivas alterações.

Ocorre que a área pública brasileira vem sofrendo profundas modificações, principalmente a partir do final da década de 1980. Reformas foram efetuadas no seio da administração, sendo a principal delas denominada de Reforma Gerencial, iniciada no governo do presidente Fernando Collor de Mello e implementada no governo do presidente Fernando Henrique Cardoso, por meio do Plano Diretor da Reforma do Aparelho do Estado (Pdrae). Tal reforma modificou o conjunto do aparelho estatal direto, a administração indireta e inseriu entidades privadas na gestão e prestação de serviços públicos sem necessidade de licitação.

As fundações públicas de direito privado, apesar de existirem, há bastante tempo, como entes da administração indireta brasileira, foram reformuladas e inseridas novamente com o advento do gerencialismo na forma de prestação dos serviços públicos pelo Estado. Tais entes da administração pública foram institucionalizados pelo Decreto-Lei ${ }^{\circ}$. 200, de 1967, segundo o qual as fundações seriam entidades dotadas de personalidade jurídica de direito privado, sem fins lucrativos, criadas em virtude de autorização legislativa para o desenvolvimento de atividades que não exijam execução por órgãos ou entidades de direito público, com autonomia administrativa, patrimônio próprio gerido pelos respectivos órgãos de direção e funcionamento custeado por recursos da União e de outras fontes.

Com o advento da Constituição Federal de 1988, algumas mudanças foram importantes para modificar o contexto e o processo de criação das fundações. O artigo 39, caput, da $\mathrm{CF} / 88$, esclarece que somente por lei específica poderá ser criada autarquia e autorizada a instituição de empresa pública, sociedade de economia mista ou fundação, cabendo à lei complementar, no último caso, definir as áreas de sua atuação em seu texto original. No entanto, a CF/88 somente prevê a criação por lei específica e não regulamenta, naquele momento, as fundações. A única menção da atual Constituição em relação a tais entes federativos é que estes possuam regime jurídico único aos servidores das fundações públicas (caput do artigo 39). É importante ressaltar, neste momento, que embora existam Fundações, estas têm uma lacuna legal que ainda não foi preenchida por Lei específica.

Apesar da previsão para a existência de fundações públicas de direito privado na Constituição Federal, não houve regulamentação por meio de lei específica - e a contratação de funcionários também não é regulamentada. Dessa forma, quase 25 anos da promulgação da $\mathrm{CF} / 88$ e de algumas tentativas serem efetuadas pelo executivo (como o Projeto de Lei no .92 , de 2007), ainda não há regulamentação para essa prática, que vem se expandindo no Estado do Rio Grande do Sul (vide os casos de criação de fundação pública de direito privado em Porto Alegre, Novo Hamburgo e Sapucaia), e em todo o Brasil, com a criação da Empresa Brasileira de Serviços Hospitalares (Ebserh).

Acerca da Reforma Gerencialista, a primeira observação importante acerca do tema é que não se pode confundir a Reforma Gerencial com o Pdrae, pois este surgiu para reafir- 
mar o modelo de governo gerencialista o Pdrae era, segundo Bresser-Pereira (2001, p. 22), "o documento básico da reforma", orientava a "ação reformadora do governo" e tentava "definir as instituições e estabelecer as diretrizes para a implantação de uma administração pública gerencial no país". Além do Pdrae, a emenda constitucional no . 17, de 1988, também é considerada um dos documentos básicos da reforma; por isso, Bresser- Pereira (2001, p. 22) afirma que "é preciso, portanto, não confundir a Reforma Gerencial de 1995 com emenda constitucional, apresentada pelo governo em 1995, que ficou chamada de reforma administrativa".

Segundo Bresser-Pereira (2001, p. 21-22), as informações necessárias à Constituição foram recolhidas em uma "viagem feita à Inglaterra onde estudou a nova gestão pública lá construída". Além disso, o autor da reforma considera que "o Brasil retrocedeu enormemente em relação aos outros países com a Constituição de 1988" e, por esse motivo, ele constrói um plano que objetiva remodelar e modificar esse retrocesso.

No intuito de compreender a historicidade das formas de administração pública brasileira, Bresser-Pereira distingue três formas ocorridas no Brasil: a patrimonialista, a pública burocrática e a gerencial. $\mathrm{O}$ autor argumenta que nos documentos feitos por ele e nos trabalhos publicados sobre a Reforma da Gestão Pública de 1994 ele sempre efetuou a distinção entre as formas de administração pública que antecederam o gerencialismo: a administração pública patrimonialista e a administração pública burocrática. Para o autor, a primeira confundia o patrimônio público com o privado e a segunda torna o serviço público profissional ancorado no princípio do mérito. O autor $(2004$, p. 13) aponta ainda que não subestimou os elementos já existentes na administração pública brasileira, mas "avançou na direção de uma administração mais autônoma e mais responsabilizada perante a sociedade, a partir do pressuposto de que a melhor forma de lutar contra o clientelismo e outras formas de captura do Estado é dar um passo adiante e tornar o Estado mais eficiente e mais moderno".

O gerencialismo seria um método para o país adaptar-se ao novo modo neoliberal e globalizado de sociedade. Para tanto, o Clad aponta o gerencialismo como a forma de o Estado preparar-se para as mudanças vindas da globalização, no intuito de transformar os países latino-americanos em países liberais, globalizados e inseridos no cenário mundial. Acerca disso, a Agenda Nacional de Gestão Pública do ano de 2009 (p. 6) afirma que "a reinvenção, para o setor público, de práticas e de paradigmas tradicionalmente associadas ao setor privado representa apenas parte pequena, embora importante, da obra a executar".

A principal referência concreta da NGP foi o modelo inglês. Na Inglaterra, com a vitória de Margaret Thatcher, em 1979 e a consequente hegemonia obtida pelo Partido Conservador até 1997 , foram estabelecidas reformas que tiveram as seguintes características, segundo Ana Paula Paes de Paula (2005, p. 47):

[...] descentralização do aparelho de Estado, que separou as atividades de planejamento e execução do governo e transformou as políticas públicas em monopólio dos ministérios; privatização das estatais; terceirização dos serviços públicos; regulação estatal das atividades públicas conduzidas pelo setor privado; uso de ideias e ferramentas gerenciais advindas do setor privado. 
Bresser-Pereira (2002, p. 13) aponta as características desse novo Plano. Afirma que a reforma da gestão pública "cria novas instituições e define novas práticas que permitem transformar os burocratas clássicos em gestores públicos". Dessa forma, o autor aponta que o objetivo central era de "reconstruir a capacidade do Estado, tornando-o mais forte do ponto de vista administrativo, e, assim criando condições para que seja também mais forte em termos fiscais e em termos de legitimidade democrática" (BRESSER-PEREIRA, 2002, p. 13-14). Uma característica fundamental do modelo é o controle total sobre o administrador público, no intuito de evitar a corrupção e o desperdício, entre outros males.

\footnotetext{
É preciso lutar contra a corrupção e o desperdício, mas essa luta não alcança êxito se nos limitamos a travar a administração pública com controles e mais controles. Ao invés disso, é preciso tornar combinar confiança com controle, dar mais autonomia ao gestor público, e fazê-lo mas responsabilizado pelos seus atos (BRESSER-PEREIRA, 2004, p. 13).
}

Outra característica importante do modelo gerencial remete ao enxugamento do aparato do Estado, feito por meio da descentralização dos serviços. No entanto, muitos críticos do modelo apontam que o que houvera no Brasil denominava-se desconcentração, já que o poder de decisão continuava centralizado. Para explicar a diferença entre os termos, Caubet (2004, p. 116) aponta que "A descentralização, pois, é uma modalidade democrática e democratizante de divisão do poder. Enquanto que a desconcentração é apenas uma modalidade de gestão administrativa, que preserva o poder de decisão da autoridade que a decide".

Em relação à saúde, a busca pela efetivação da descentralização vem ocorrendo há muito tempo. Prova disso é que, em 1963, a Conferência Nacional de Saúde já discutia a importância de tal descentralização dos serviços e, em 1992, a questão da municipalização trata exatamente de aumentar o poder dos municípios. Além disso, um dos princípios fundamentais do SUS fala da importância de descentralizar tais serviços.

Além da desconcentração, há também a questão da publicização e da diminuição das vagas no funcionalismo público, sempre tentando diminuir o tamanho do Estado, pois, segundo Bresser-Pereira (2004, p. 14), “os gestores públicos devem ser relativamente poucos, apenas os necessários para executar atividades exclusivas de Estado". A questão da descentralização é uma das maiores discussões desse modelo, já que alguns autores afirmam que se trata de uma máscara para a privatização dos serviços estatais. Acerca disso, Dasso Junior (2006, p. 178) aponta que:

\footnotetext{
A criação de entes descentralizados, que atuam nos serviços sociais e científicos para o denominado "setor público não estatal" representa a privatização dos serviços públicos na área social. O exame das características da "Nova Gestão Pública" permite conceituá-la como uma teoria de Administração Pública que adota um enfoque empresarial para a gestão, dando ênfase à redução de custos, à eficácia e à eficiência dos aparelhos de Estado e propondo a clientelização dos cidadãos.
}

Isso ocorre pelo fato de que o modelo gerencial se inspirou na gestão privada para conceber um novo modelo público, no Brasil. No entanto, Dasso Junior (2006, p. 179) afir- 
ma que "inspirar-se na gestão privada é um erro conceitual grave, porque a gestão pública é, pelos fins e meios, absolutamente diferente da gestão privada". Tal discussão amplia-se atualmente para as formas escolhidas pela gestão pública para prestar seus serviços. Portanto, neste momento torna-se imperativo verificar a constituição do SUS e, a partir daí, discutir a prestação dos serviços de saúde. Para isso, será feita, primeiramente, uma breve revisão histórica acerca do próprio SUS, para compreender o fenômeno que o criou, e, após, verificarmos como se dá tal prestação de serviço. Tudo isso para compreender as origens das fundações públicas de direito privado na saúde pública.

\section{A IDEALIZAÇ̃̃o DO MOVIMENTO SANITARISTA BRASILEIRO}

Inicia-se a descrição a partir do Brasil Colônia e do Império. Em tal época, a preocupação era apenas com questões de controle de saúde em navios e portos, sendo tais responsabilidades delegadas às juntas municipais. Somente no ano de 1851 é criada a Junta Central de Higiene Pública, que tinha por objetivo aumentar os cuidados de saúde e promover campanhas. Nesse sentido, a Junta inspecionava a vacinação, controlava a política sanitária da terra e a medicina em geral. Para tanto, os alimentos, farmácias, armazéns, cemitérios etc. eram inspecionados, já que tais lugares poderiam causar danos à saúde pública (Ministério da Saúde).

Oliveira (1983), ao abranger o período de 1866-1896 da história da saúde brasileira, em especial no Estado da Bahia, esclarece o papel de intelectuais formuladores de discursos científicos e políticos, em especial aqueles dirigidos a promover a intervenção médica no corpo social. Ele aponta que é possível estudar "os projetos médico-sociais, como uma das bases sobre a qual se apoiam tentativas de dominação de uma determinada fração ou classe sobre as demais" (OLIVEIRA, 1983, p. 102). O autor também analisa a forma como foi estruturado o modelo que compreende o sanitarismo no Brasil. Para isso, toma as propostas desenvolvidas por dois grupos contemporâneos: a Sociedade de Medicina e Cirurgia do Rio de Janeiro e a Escola Tropicalista Baiana.

A proclamação da República, em 1889, e a modernização do Brasil, iniciada a partir desse período, foram importantes para melhorar as condições de saúde sanitária da população. Nesse momento, a população brasileira ainda era rural e com altos índices de analfabetos e doentes, fato esse que impulsionou o movimento sanitarista. Tal contexto inicia discussões sobre questões sociais, entre elas a saúde. Na Constituição Federal de 1891 é notável certa mudança em relação à saúde, sendo que existiam políticas sociais para essa área e responsabilização dos Estados pelas ações de saúde, saneamento e educação.

Nesse período, as principais enfermidades que acometiam a população eram as epidemias da varíola, malária, febre amarela e, mais tarde, peste bubônica. Esses problemas, associados à falta de controle por parte dos Estados, trouxeram consequências econômicas, visto que navios estrangeiros não atracariam mais no porto do Rio de Janeiro. Em função disso, o governo republicano, auxiliado pela incorporação de novos conhecimentos clínicos e epidemiológicos, resolveu, de acordo com documento do Conselho Nacional de Secretários da Saúde (Conass) (2009), elaborar planos para combater as enfermidades, que diminuíam a vida útil da população. Além disso, o Conass (2009) aponta que, de modo diferente daquilo 
que vinha ocorrendo, a participação do Estado nas esferas de saúde aumentou, ampliando da pequena questão das epidemias para todos os setores da sociedade. O movimento sanitarista contribui, também, para a criação do Departamento Nacional de Saúde (DNS), em 1920, que, segundo o Ministério da Saúde, seria o responsável por uma série de serviços e campanhas direcionados para o controle de doenças, como a febre amarela e a malária.

Em 1923, foi aprovada a Lei Eloi Chaves e a assistência médica teve um reconhecimento legal como política pública. Essa lei regulamentou a criação das Caixas de Aposentadorias e Pensões (CAPs), que eram organizações de direito privado, criadas para grupos específicos de servidores que recebiam benefícios de acordo com suas contribuições. Segundo o Conass (2009), nessa modalidade de seguridade o Estado não tinha participação, uma vez que se tratava de um sistema por empresa e estava bastante restrito às grandes corporações privadas e públicas existentes no país. Cada CAP possuía administração própria para os seus fundos, formada por um conselho constituído por representantes de empregados e empregadores.

No primeiro governo de Getúlio Vargas, houve certa mudança no cenário da previdência social, já que a política de Estado tratava de ampliar o benefício da previdência às categorias do operariado urbano organizado. As CAPs foram substituídas pelos Institutos de Aposentadoria e Pensões, que passaram a ser a categoria dos funcionários marítimos, comerciários e bancários. Ainda em meados dos anos de 1950, foi criado o Ministério da Educação e Saúde Pública, que atendia àqueles não incluídos na medicina previdenciária. A esse órgão competia, segundo o Conass (2009, p. 19), a prestação de serviços daqueles identificados como "pré-cidadãos", ou seja, pobres, desempregados, todos que exerciam atividades informais e todos os que não se encaixavam nos serviços das CAPs e da previdência.

Em 1953, foi criado o Ministério da Saúde (MS), ao qual couberam as atividades que eram de responsabilidade do DNS, sendo apenas um instrumento legal das ações. De fato, o MS era a principal unidade administrativa de ação sanitária ligada ao governo; entretanto, essa função era distribuída entre outros ministérios e autarquias, o que acabava gerando uma disseminação de recursos financeiros e de pessoal técnico.

Segundo o MS, a década de 1960, no Brasil, foi marcada por problemas por conta do abismo social existente entre as camadas sociais da população, o que fez levantar o discurso sanitarista em torno das relações entre saúde e desenvolvimento. Os sanitaristas buscavam uma adequação entre o planejamento de metas de crescimento e melhorias com o planejamento em saúde. Entre as propostas para adaptar os serviços de saúde pública à situação que fora diagnosticada pelos sanitaristas, está a Formulação Nacional de Saúde, que teve como objetivo redefinir a identidade do MS e colocá-lo em sintonia com os avanços verificados na esfera econômico-social. Além disso, o Conass (2009) aponta que o contexto envolto nas decisões que levaram a definir melhor a identidade do MS, já mencionadas, era o da realização da III Conferência Nacional de Saúde, em 1963, que previa em seu artigo $1^{\circ}$., parágrafo único, tratar de problemas de saúde e assistência, principalmente a questão da fixação de um plano nacional de saúde, fator importante nas discussões feitas à época.

Posteriormente, entre 1964 e 1984, foi implantado o Sistema Nacional de Saúde. No intuito de centralizar a questão previdenciária, os militares unificaram os Institutos de Aposentadoria e Pensões e instituíram o Instituto Nacional de Previdência Social (INPS), que, 
segundo o Conass (2009), concentrava todas as contribuições previdenciárias, além de o órgão gerenciar as pensões e assistências médicas de todos os trabalhadores formais, embora deva ser ressaltado que uma gama de trabalhadores informais estava fora desse órgão.

Posteriormente, o INPS foi desdobrado em outros três institutos: Instituto de Administração da Previdência Social, Instituto Nacional de Previdência Social e Instituto Nacional de Assistência Médica da Previdência Social (Inamps) - que atendia somente aos trabalhadores com carteira assinada. Segundo Souza (2002), nessa época os brasileiros dividiam-se em três categorias quanto à assistência à saúde: os que poderiam pagar pelos serviços, os que tinham direito à assistência prestada pelo Inamps e aqueles que não possuíam direito algum. Mesmo com a grande expansão desse modelo de assistência, por meio de construção de hospitais e compras de leitos, o sistema entrou em crise, com a crise econômica dos anos 1970 e 1980.

Por conta da situação existente na saúde brasileira, houve a rearticulação de movimentos sociais que reivindicavam soluções para os problemas existentes naquele momento. Entre vários movimentos, destaca-se o movimento sanitário, que procurava conciliar a produção do conhecimento e a prática política, por meio da chamada medicina social. A ideia era atender a todas as camadas da população, proporcionando atendimento igualitário. Acerca disso, a Declaração de Alma - Ata (1978), feita em uma das Conferências Internacionais de Saúde, foi essencial para reafirmar as discussões levantadas pelos sanitaristas, já que essa se manifestava a favor da acessibilidade dos serviços médicos a toda população.

Os anos 1980 são marcados por reivindicações ao sistema de saúde governamental. A democratização do sistema, o acesso universal, a defesa do caráter público e a descentralização eram algumas das propostas de mudanças. Assim, a saúde seria vista como direito humano fundamental - um direito social. O marco dessa década foi a realização da VIII Conferência Nacional de Saúde, em 1986, que resultou na legitimação dos princípios e da doutrina do Movimento da Reforma Sanitária. Um ponto importante que este documento aborda é a questão do conceito de saúde, que foi ampliado e é resultante de outros fatores como, por exemplo, habitação, lazer, alimentação, emprego e outros. Além do fato de que a saúde passou a ser vista como um direito garantido pelo Estado.

Assim, após lutas por condições dignas de assistência à saúde, foi criado, na VIII Conferência Nacional de Saúde, o Sistema Único de Saúde, uma proposta nova de modelo de saúde, com separação total da saúde em relação à Previdência. Outro tema importante do SUS é a cobertura universal, além da previsão de participação social - ideias essas que são frutos do Movimento Sanitarista em prol da democratização do nosso país. A nova Constituição Federal, promulgada em 1988, trouxe conquistas como a responsabilização dos agentes públicos por má administração e a preocupação com os direitos individuais, e ainda aprovar direitos civis e políticos. E, de modo muito significativo, garantiu saúde e seguridade social a todos os brasileiros. Dessa forma, após anos de luta dos chamados sanitaristas (aqueles que pertenciam ao Movimento de Reforma Sanitária), o direito à saúde é apontado na $\mathrm{CF} / 88$ como universal, ofertado a todos de forma igualitária pelo Estado.

$\mathrm{Na} \mathrm{CF} / 88$, os direitos fundamentais (especificamente a saúde) estão dispostos no Título II, Capítulo II - "Os direitos sociais". Sendo que o artigo $6^{\circ}$. da CF/88 ressalta que "São direitos sociais a educação, a saúde, o trabalho, a moradia, o lazer, a segurança, a previdên- 
cia social, a proteção à maternidade e à infância, a assistência aos desamparados, na forma desta Constituição" (BRASIL, CF/88, 2004, p. 20, grifo do autor). A CF/88 confere à saúde o status de direito social e responsabiliza o Estado pela prestação adequada e pelo fornecimento a todos, garantindo, assim, as condições mínimas para a dignidade da pessoa humana. Nesse sentido, o artigo 196 da CF/88 (2004, p. 117) vem reafirmar a importância do direito à saúde: "A saúde é direito de todos e dever do Estado, garantido mediante políticas sociais e econômicas que visem à redução do risco de doença e de outros agravos e ao acesso universal e igualitário às ações e serviços para sua promoção, proteção e recuperação".

O arcabouço legal do SUS está explicitado no texto da CF/88, nas constituições estaduais e nas leis orgânicas dos municípios, que incorporaram e detalharam os princípios da Carta Magna brasileira. As Leis Orgânicas da Saúde (LOS) são as responsáveis pela regulamentação do SUS, explicitando a organização e o funcionamento do sistema. São um conjunto de duas leis editadas, a Lei $n^{\circ} .8 .080$ e a Lei $n^{\circ} .8 .142$, ambas sancionadas em 1990, com o objetivo de, segundo Gilberto Natalini (2001, p. 28):

\footnotetext{
[...] dar cumprimento ao mandamento constitucional de disciplinar legalmente a proteção e a defesa da saúde. [...] contém diretrizes e os limites que devem ser respeitados pela União, pelos Estados e pelos municípios ao elaborarem suas próprias normas. São destinadas, portanto, a esclarecer o papel das esferas de governo na proteção e na defesa da saúde, orientando suas respectivas atuações para garantir o cuidado da saúde.
}

Os princípios do SUS são: a universalidade de acesso aos serviços de saúde em todos os níveis de assistência; confirmando o artigo 196, onde a saúde é direito de todos; a integralidade de assistência, que pressupõe considerar as várias dimensões do processo saúde - doenças que afetam os indivíduos e as coletividades, com prestação continuada das ações e serviços preventivos e curativos, exigidos para cada caso em todos os níveis de complexidade do sistema; a equidade, isto é, a igualdade da assistência à saúde, priorizando a oferta de ações e serviços aos segmentos populacionais considerados de maior risco de adoecimento e morte decorrente da desigualdade na distribuição de renda, bens e serviços; e o direito à informação, às pessoas assistidas, sobre sua saúde e os riscos e condicionantes que afetam a saúde coletiva, atribuindo aos profissionais e aos gestores a responsabilidade por viabilizar esse direito.

Já as diretrizes do sistema são: descentralização político-administrativa, com direção única em cada esfera de governo e ênfase na descentralização dos serviços para os municípios; conjugação dos recursos financeiros, tecnológicos, materiais e humanos da União, dos Estados, do Distrito Federal e dos municípios, na prestação de serviços de saúde; participação da comunidade, que demonstra o desejo dos atores sociais por uma democracia participativa, onde os cidadãos influenciam de maneira decisiva a definição e a execução da política de saúde nas três esferas de governo; e regionalização e hierarquização.

Resta evidente que a historicidade acerca da saúde pública brasileira e consequente criação do SUS aponta para uma luta constante dos movimentos em prol de uma saúde universal, gratuita e de qualidade aos cidadãos. Além disso, a construção e consolidação de novas formas de prestação dos serviços de saúde propõe novos entes ainda não legitimados pelas leis apropriadas e que podem ocasionar problemas na prestação dos serviços de saúde. 


\section{CONSIDERAÇõES FINAIS}

Portanto, após efetuar uma retrospectiva acerca do gerencialismo, do SUS e de sua legislação pertinente, é imperativo verificar qual foi o impacto na saúde pública brasileira desse novo sistema de governo, visto que a nova Constituição que impera direitos sociais diversos é do ano de 1988 e o projeto gerencial inicia-se no ano de 1994, com as pesquisas feitas por Bresser-Pereira.

Estudou-se o SUS, em uma retrospectiva sobre os acontecimentos da história do Brasil que fizeram que esse sistema de saúde fosse criado. Lembrando, inclusive, de aspectos importantes, como o Movimento Sanitarista, que acompanhou e lutou pelo SUS - e ainda o acompanha, sempre preocupado com a manutenção dos direitos auferidos pela Constituição Federal de 1988.

Após, verificou-se como a Reforma Gerencial, proposta na década de 1990, no Brasil, pelo ex-presidente Fernando Henrique Cardoso, inserindo novos pensamentos de gestão, advindos do setor privado para dentro da gestão pública municipal - além de haver modificado a prestação de serviços de saúde, por meio da criação de novas formas de gestão de tais serviços. E ainda, mesmo que ainda que existam discussões sobre a legalidade das Fundações Públicas de Direito Privado, servem para que sejam estudados e discutidos, ainda que, ao final, sejam deixados de lado pela administração, por serem considerados inconstitucionais, ou por outro motivo qualquer. O que importa é que, se tais meios existem, se há a possibilidade de estudá-los, cabe ao pesquisador fazê-lo.

Ressalta-se que este trabalho não se encerra aqui. São imprescindíveis análises acerca das novas formas de gestão na saúde pública brasileira, visto que são escassos tais estudos. Além disso, seria interessante verificar as mudanças ocorridas na prestação dos serviços de saúde aos cidadãos, pois essa parcela de participação não foi objeto da pesquisa, que procurou trabalhar com a sociedade organizada.

\section{REFERÊNCIAS}

BRASIL. Agenda nacional de gestão pública. Brasília: Imprensa Nacional, 2009.

. Câmara da Reforma do Estado. Plano diretor da reforma do aparelho do estado Brasília, 1995.

. Conselho Nacional de Secretários de Saúde. SUS 20 anos. Brasília: CONASS, 2009.

. Constituição da República Federativa do Brasil. Brasília: Senado Federal, 2004.

. Decreto-Lei $\mathbf{n}^{\mathbf{0}}$. 200, de 25 de fevereiro de 1967. Texto original, revogado pelo Decreto-Lei no ${ }^{\circ}$.900, de 1969. 
. Decreto-Lei no .900 , de 29 de setembro de 1969. Texto original.

\section{. Emenda Constitucional no. 17, de 22 de novembro de 1997.}

. Lei nº 8.080, de 19 de setembro de 1990. Brasília, 1990. Disponível em: http:// portal.saude.gov.br/portal/arquivos/pdf/LEI8080.pdf. Acesso em: 16 out. 2011.

. Lei no. 8.142, de 28 de dezembro de 1990. Brasília, 1990. Disponível em: http:// www.planalto.gov.br/ccivil_03/leis/L8142.htm. Acesso em 10 nov. 2012.

. Projeto de Lei $\mathbf{n}^{\mathbf{0}}$. 92, de 2007. Dispõe sobre as áreas de atuação das fundações públicas e dá outras providências, 2007.

BRESSER-PEREIRA, Luiz Carlos. Instituições, bom Estado, e reforma da Gestão Pública. In: BIDERMAN, Ciro; ARVATE, Paulo (Orgs.). Economia do Setor Público no Brasil. São Paulo: Campus Elsevier, 2004.

. Uma resposta estratégica aos desafios do capitalismo global e da democracia. In: BRASIL. Ministério do Planejamento, Orçamento e Gestão. Balanço da reforma do Estado no Brasil: a nova gestão pública. Brasília: Seminário de 6 a 8 de agosto de 2002 .

. Do estado patrimonial ao gerencial. In: Pinheiro, Wilheim e Sachs (Orgs.), Brasil: Um Século de Transformações. São Paulo: Cia das Letras, 2001.

CAUBET, Christian Guy. A água, a lei, a política... e o meio ambiente? Curitiba: Juruá, 2004.

CLAD, Centro Latino-Americano de Administração para o Desenvolvimento. Uma nova gestão pública para a América Latina. Documento em espanhol, português e inglês, preparado pelo Conselho Científico e aprovado pelo Conselho Diretor do CLAD, 14 de outubro, 1998.

CONSELHO NACIONAL DE SAÚDE. Disponível em: http://conselho.saude.gov.br. Acesso em: 20 ago. 2012.

FLICK, Uwe. Desenho da pesquisa qualitativa. Porto Alegre: Bookman, 2009.

MINISTÉRIO DA SAÚDE DO BRASIL. Portal da Saúde. Disponível em: http://portalsaude.saude.gov.br/portalsaude/. Acesso em: 20 jan. 2013.

NATALINI, Gilberto. Princípios básicos do SUS. In: SUS - o que você precisa saber sobre o Sistema Único de Saúde, v. II, p. 21-34. São Paulo: Associação Paulista de Medicina, 2000. 
OLIVEIRA C. R. Medicina e Estado, origem e desenvolvimento da medicina social na Bahia: 1866-1896. Dissertação de mestrado. Instituto de Medicina Social, Universidade do Estado do Rio de Janeiro, 1983.

PAES, Jose Eduardo Sabo. Fundações: Origem e evolução histórica. Revista de Informação Legislativa. Brasília a. 35 n. 140 out./dez. 1998.

PAULA, Ana Paula Paes de. Por uma nova gestão pública: limites e potencialidades da experiência contemporânea. Rio de Janeiro: Editora FGV, 2005.

RAFAEL, Edson José. Fundações e Direito: terceiro setor. São Paulo: Melhoramentos, 1997

SOUZA, Renilson Rehem de. O sistema público de saúde brasileiro. In: Tendências e desafios dos sistemas de saúde nas Américas, 2002, São Paulo. Seminário Internacional, 11 a 14 de agosto de 2002 .

\section{Estéfani Sandmann Sandmann de Deus}

Doutora em Administração pela Universidade Federal do Rio Grande do Sul. Mestra em Ciências Sociais pela Pontifícia Universidade Católica do Rio Grande do Sul. Coordenadora do curso de Administração da Universidade Estadual do Rio Grande do Sul (UERGS) em Cachoeira do Sul. Professora Adjunta do Curso Administração da UERGS. Professora Adjunta do Curso de Agronomia da UERGS. Professora da Especialização em Gestão e Desenvolvimento Rural da UERGS.

estefanideus@gmail.com

\section{TAINARA Rodrigues Krusser}

Acadêmica do Curso de Administração da Universidade Estadual do Rio Grande do Sul. tainara-krusser@uergs.edu.br

Submetido em: 8-10-2020

Aceito em: 13-11-2020 